\title{
Cognition: from Physiology to Sociology and Back
}

\author{
Paolo Grigolini* \\ UNT professor of Physics, University of North Texas, USA
}

Submission: December 17, 2018; Published: January 24, 2019

"Corresponding author: Paolo Grigolini, UNT professor of Physics, Center for Nonlinear Science, University of North Texas, P.0. Box 311427, Denton, Texas 76203-1427, USA

Keywords: Life Evolution; Self-Organization; Crucial Events; Self-Managed Work Teams Opinion

\section{Opinion}

The recent literature on cognition shows that different disciplines, from biology to psychology, addressing the unsettled problem of information processing, are converging towards a widely shared conjecture: intelligence is the result of a process of self-organization. Interdisciplinary unification is expected to lead to a mathematical model establishing a bridge between life evolution and sociology. Preliminary results show that genuinely spontaneous organization generates intelligent crucial events, namely changes of flying direction adapting the self-organizing society to the environment. Moving from biology to cultural anthropology makes us realize that the organization process may be affected by cognition killing top-down influences. The lack of intelligence has the effect of generating organization collapses. All this suggests that the most benecial forms of management are horizontal rather than vertical.

The cognition issue is of central importance for biology. Life evolution is closely connected to information processing [1] and life and consciousness, very difficult to explain using ordinary physics [2], are affording the stimulus for a new cosmological theory [2]. The new theory, inspired to life evolution, should assume that the universe evolves in time and the new theoretical perspective should turn the origins of stars, life and consciousness from being extremely improbable, according to the current physics, into the emergent processes that are observed and studied.

Quantum mechanics, although remaining at the level of strange simplicity [3], is exerting a strong influence on researchers looking for the origin of consciousness [4,5], which is assumed to be related to quantum mechanical coherence. This assumption, however, may violate the attractive arguments of black holes scientists that the unification of gravity and quantum mechanics requires quantum mechanical decoherence rather than coherence. Tegmark [6] shows that quantum mechanical decoherence is so fast that we must study the brain using classical physics.
In conclusion, we are inclined to adopt a different interpretation to explain the emergence of cognition. A widely accepted argument is that cognitive systems, including the brain, are systems at criticality $[7,8]$. Criticality is the edge of phase transition, from a set of units with independent random dynamics to a condition of organization. The ordinary phase transitions are generated by assigning to a control parameter, for instance temperature, a critical value. The processes leading to cognition must be spontaneous, thereby involving the idea of Self-Organized Criticality (SOC) [9], proposed in 1988.

This theory focuses on the generation of avalanches with a size distribution density described by an inverse power law. More recently another form of spontaneous organization was proposed [10], called Self-Organized Temporal Criticality (SOTC), which establishes a more transparent connection with cognition. This is so because SOTC generates crucial events, which can be interpreted as changes of flying direction, allowing the self-organizing system to adapt to its environment. In fact, the complexity of crucial events is defined by the time distance between two consecutive events, which is described by an inverse power law distribution. Thus, with SOTC complexity is temporal rather than related to the intensity of fluctuations. Using the concepts of Kolmogorov complexity, it is possible to prove that crucial events convey meaningful information, this being a clear sign of cognition [11].

Difficult tasks and diseases have the effect of turning the crucial events into ordinary random processes, corresponding to moving the system from the critical to subcritical condition [8], thereby affording new methods for diagnosis and medical therapies. This is where a surprising connection with sociology and management emerges. In fact, while the emergence of cognition is biological, sociology requires that we move from biology to anthropology interpreted as an extension of the Darwin life evolution. This leads us to move from the bottom-up processes to top-down forms 
of organization. It is shown [12] that the top-down approach to organization makes the healthy crucial events of SOTC become the source of true organization collapses.

This observation has a great importance for the management issue. In fact, a top-down organization is associated to a hierarchical structure, while the bottom-up organization is realized through horizontal structures. Based on Ref [12] I conclude that the horizontal is more efficient than the vertical approach to organization. This is in line with the sociology researchers of Ref [13]. These authors notice that since the mid1970s, international competition has forced U.S. businesses to look for the best way to achieve and maintain a competitive position. Their 1998 book prove that the Self-Managed Work Teams (SMWT) are the most efficient forms of organization to achieve high performance at the minimal cost. Examples of the efficiency of the success of self-management are given by a team of performing musicians adopting the SMWT prescription [14] and by the US rms successfully adopting self-management [15].

I believe that SOTC will establish a bridge between the biological origin of cognition and the most efficient form of management, according important contributions to the increasingly popular issue of how to anticipate the future [15]. This debate is deeply related to neuroscience [16], thereby moving me back from social management to the origin of cognition.

\section{Acknowledgment}

The author thanks ARO for financial support of the proposal "Self-organization of social systems" through the grant W911NF1901.

\section{References}

1. WB Miller Jr (2018) Biological information systems: Evolution as cognition-based information management. Progress in Biophysics and Molecular Biology 134: 1-26.

2. L Smolin (1997) The Life of the Cosmos, Oxford University press, New York, USA.
3. M Eigen (2013) From Strange Simplicity to Complex Familiarity: A Treatise on Matter, Information, Life and Thought, Oxford University Press, Oxford UK.

4. JS Torday, WB Miller Jr (2018) The Cosmologic continuum from physics to consciousness. Progress in Biophysics and Molecular Biology 140: 41-48.

5. FA Popp (2008) Consciousness as Evolutionary Process Based on Coherent States, NeuroQuantology 6: 431.

6. M Tegmark (2000) Importance of quantum decoherence in brain processes, Phys. RevE 61: 4194.

7. DR Chialvo (2010) Emergent complex neural dynamics. Nat Phys 6: 744 .

8. L Cocchi, LL Gollo, A Zalesky, M Breakspear (2017) Criticality in the brain: A synthesis of neurobiology, models and cognition. Progress in Neurobiology 158: 132.

9. P Bak, C Tang, K Wiesenfeld (1988) Self-organized criticality. Phys Rev A 38: 364.

10. K Mahmoodi, BJ West, P Grigolini (2017) Self-organizing Complex Networks: individual versus global rules. Frontiers in Physiology 8: 478.

11. P Allegrini, V Benci, P Grigolini, P Hamilton, M Ignaccolo, et al. (2003) Compression and diffusion: a joint approach to detect complexity, Chaos. Solitons \& Fractals 15: 517-535.

12. K Mahmoodi, BJ West, P Grigolini (2018) Self-Organized Temporal Criticality: Bottom-Up Resilience versus Top-Down Vulnerability. Hindawi complexity 2018: 8139058.

13. DE Yeatts, C Hyten (1998) High-Performing Self-Managed Work Teams: A Comparison of Theory to Practice, Sage Publications, International Educational and Professional Publisher, Thousand Oak, USA.

14. M TalShmotkin, A Gilboa (2013) Do behaviors of string quartet ensembles represent self-managed teams? Team Performance Management 19: 57.

15. M Attaran, TT Nguyen (2000) Creating the right structural fit for selfdirected teams. Team Performance Management 6: 25.

16. J Illes (2017) Neuroethics: Anticipating the Future, Oxford University Press, Oxford, UK.

\begin{tabular}{|l|}
\hline \multicolumn{1}{|c|}{ Your next submission with Juniper Publishers } \\
will reach you the below assets \\
- Quality Editorial service \\
- Swift Peer Review \\
- Reprints availability \\
- E-prints Service \\
- Manuscript Podcast for convenient understanding \\
- Global attainment for your research \\
- Manuscript accessibility in different formats \\
( Pdf, E-pub, Full Text, Audio) \\
- Unceasing customer service \\
Track the below URL for one-step submission \\
https://juniperpublishers.com/online-submission.php \\
\hline
\end{tabular}

